\title{
POSSIBILIDADES PARA ENSINAR E APRENDER SOBRE VOLUME E CAPACIDADE NOS ANOS INICIAIS DO ENSINO FUNDAMENTAL
}

\author{
POSSIBILITIES FOR TEACHING AND LEARNING VOLUME AND \\ CAPACITY CONCEPTS AT EARLY YEARS OF ELEMENTARY SCHOOL
}

\author{
SIMONE POZEBON 1 \\ MAIARA LUISA KLEIN ${ }^{2}$ \\ IASMIM MARTINS NORO ${ }^{3}$
}

\section{RESUMO}

Entendendo que algumas problematizações possibilitam que professor e aluno se coloquem em movimento de aprendizagem e que a intencionalidade do professor é fundamental no processo de organização do ensino, busca-se na pesquisa discorrida neste artigo identificar indícios de aprendizagem de volume e capacidade a partir de uma situação desencadeadora de aprendizagem. Fundamentadas nos pressupostos da Teoria Histórico-Cultural, especialmente da Atividade Orientadora de Ensino, as ações aqui analisadas foram desenvolvidas pelos participantes do projeto Clube de Matemática da Universidade Federal de Santa Maria (UFSM) em uma turma de $4 .{ }^{\circ}$ ano de uma escola pública de Santa Maria - RS. As análises indicam que, no processo de ensino e aprendizagem, os alunos conseguiram estabelecer uma relação entre os conceitos de volume e capacidade e que é possível utilizar materiais sensoriais na sua abordagem. Assim, com base na situação realizada, depreendemos ser potente e importante trabalhar essas grandezas nos anos iniciais, alcançando sínteses conceituais.

Palavras-chave: Atividade Orientadora de Ensino. Situação desencadeadora de aprendizagem. Volume e capacidade.

\section{ABSTRACT}

Considering that certain problematizations allow teachers and students to put themselves in a learning movement and that the teacher's intentionality is fundamental to the teaching organization process, the research carried out in this article seeks to identify signs of learning volume and capacity concepts from a triggering learning situation, in the early years of elementary school. Based on the assumptions of the Historical-Cultural Theory, especially the Teaching Orientation Activity, the actions analysed here were developed by participants of the Mathematics Club project at the Federal University of Santa Maria, in a 4th year class of a public school from Santa Maria. The analyses indicate that, throughout the teaching and learning process, students were able to establish a relationship between the concepts of volume and capacity and that it is possible to use sensory materials in their approach. Thus, based on the situation analysed, we perceive as potential and important to work these concepts during early school years, reaching conceptual syntheses.

Keywords: Teaching Orientation Activity. Triggering learning situation. Volume and capacity.

\section{RESUMEN}

Al entender que algunas problematizaciones permiten que profesor y alumno se pongan en movimiento de aprendizaje y que la intencionalidad del profesor es fundamental en el proceso de organización de la enseñanza, se busca en

1 Doutora em Educação. Universidade Federal do Rio Grande do Sul, Porto Alegre, Rio Grande do Sul, Brasil. E-mail: spozebon@gmail.com. Orcid: 0000-0002-3872-5117.

2 Mestranda do Programa de Pós-Graduação em Educação. Universidade Federal de Santa Maria, Santa Maria, Rio Grande do Sul, Brasil. E-mail: maiara103@hotmail.com. Orcid:0000-0001-5867-5375.

3 Mestranda do Programa de Pós-Graduação em Educação Matemática e Ensino de Física. Universidade Federal de Santa Maria, Santa Maria, Rio Grande do Sul, Brasil. E-mail: iasmim_mn@hotmail.com. Orcid: 0000-0002-7175-5350. 
esta investigación identificar indicios de aprendizaje de volumen y capacidad mediante una situación desarrolladora de aprendizaje, en los primeros ciclos de la Enseñanza Primaria. Basadas en la Teoría Histórico-Cultural, específicamente en la Actividad Orientadora de Enseñanza, las acciones analizadas las desarrollaron los participantes del Clube de Matemática da Universidade Federal de Santa Maria con un grupo de $4^{\circ}$ año de una escuela pública de la ciudad de Santa Maria. Los análisis indican que, en el proceso de enseñanza y aprendizaje, los alumnos lograron establecer relación entre los conceptos de volumen y capacidad y que es posible utilizar materiales sensoriales en ese proceso. A partir de ello, se deduce la potencia y importancia de trabajar esas grandezas en Primaria, logrando síntesis conceptuales.

Palabras-clave: Actividad Orientadora de Enseñanza. Situación desarrolladora de aprendizaje. Volumen y capacidad.

\section{INTRODUÇÃO}

0 conhecimento matemático foi se constituindo ao longo do processo histórico da humanidade, ressignificando-se a partir das interações que se ampliam com o passar dos tempos. Esse movimento possibilitou que novas sistematizações fossem criadas, estruturadas e utilizadas para suprir as necessidades que iam aparecendo e, consequentemente, modificando a vida em sociedade. Com o surgimento da educação escolar, os conhecimentos considerados importantes passaram a ser organizados em forma de conteúdos escolares para serem socializados às próximas gerações, na perspectiva de que, como produto cultural humano, também se constituam como instrumentos de aprimoramento de capacidades tipicamente humanas. Assim sendo, a escola é o lugar socialmente estabelecido para que os sujeitos, que estão iniciando o contato com o meio, apreendam aquilo que foi sistematizado por aqueles que os antecederam.

Com essas premissas apoiamo-nos na Teoria Histórico-Cultural, apresentada por Vigotski ${ }^{4}$ (1896-1934), que compreende 0 homem ${ }^{5}$ como um ser social e histórico e que, para humanizar-se, necessita além dos aspectos biológicos, estabelecer relações com o meio em que vive e com os integrantes do coletivo no qual está inserido, apossando-se das funções já consolidadas historicamente. Desta forma, é imprescindível que se oportunizem situações em que as novas gerações se apropriem de produtos culturais para o desenvolvimento delas.

É neste contexto que consideramos a aprendizagem como decorrência da intencionalidade do professor na organização do ensino e defendemos como opção teórico-metodológica a Atividade Orientadora de Ensino (AOE), proposta por Moura (1996), a qual aponta elementos de dupla formação que permitem ao professor e ao aluno aproximarem-se da essência do conceito com o qual irão trabalhar. É por meio da organização de situações desencadeadoras de aprendizagem (SDA), orientadas pelos princípios da $\mathrm{AOE}$, que se colocam possibilidades para 0 aluno aprender com base na compreensão do movimento lógico-histórico do conceito que acompanha o processo que o ser humano perpassou na sua criação.

Se constituindo como um conhecimento histórico elaborado pela humanidade a partir de necessidades sociais, as grandezas e medidas se configuram como produto de diferentes movimentos realizados em distintos tempos e espaços. Esses movimentos resultaram nas sistematizações atualmente utilizadas para as interações sociais, as quais são possíveis pela compreensão do conhecimento matemático.

4 Neste artigo, optamos por utilizar "Vigotski", com exceção de citações literais e referências de outros autores que apresentem de forma diferente onde a forma com que seu nome aparece da obra citada será mantida.

5 Nessa pesquisa utilizamos o termo "homem" para nos referirmos ao ser humano de maneira geral, seja homem ou mulher e não a indivíduo do sexo masculino, como normalmente é entendido. 
Desta forma, no processo de ensino e aprendizagem devem ser contemplados os conhecimentos historicamente advindos de necessidades sociais para que os novos sujeitos se apropriem desses conhecimentos. Compreendendo que grandezas e medidas são produtos históricos, elencamos os conceitos de volume e capacidade para serem abordados nas situações propostas para desencadear, nos sujeitos envolvidos, necessidades que os levam a apropriação desse conhecimento. Também percebemos que estas grandezas são pouco exploradas nos primeiros anos de escolarização, em detrimento à outras, como comprimento, massa e tempo.

Entendendo que essas situações favorecem ao professor e ao aluno se colocarem em um movimento de aprendizagem, temos como produto desse contexto o presente artigo, que objetiva identificar indícios de aprendizagem sobre volume e capacidade a partir de uma situação desencadeadora de aprendizagem, na perspectiva da Atividade Orientadora de Ensino, nos anos iniciais do Ensino Fundamental. Assim, apresentamos ações oriundas de movimentos de estudo, planejamento, desenvolvimento e avaliação no contexto do projeto Clube de Matemática (CluMat) da Universidade Federal de Santa Maria (UFSM), o qual é composto por professores do Ensino Superior e da Educação Básica, acadêmicos da pós-graduação e dos cursos de Licenciatura em Educação Especial, Matemática e Pedagogia.

Particularmente neste artigo, realizamos um recorte, oriundo de estudos realizados pelos participantes do projeto, de uma situação desencadeadora de aprendizagem em uma turma de $4 .{ }^{\circ}$ ano do Ensino Fundamental de uma escola pública do município de Santa Maria. Assim sendo, apresentamos aqui brevemente alguns dos apontamentos teóricos que subsidiaram as ações, bem como os caminhos metodológicos orientadores da pesquisa. Posteriormente, discorremos sobre 0 desenvolvimento de uma situação desencadeadora de aprendizagem e as manifestações dos alunos diante delas. Por fim, delineamos algumas considerações acerca do trabalho realizado.

\section{ALGUNS APONTAMENTOS TEÓRICOS}

Em seus estudos relacionados ao processo de constituição do ser humano e orientado pelas contribuições do materialismo histórico dialético de Marx, Vigotski $(1994,2000)$ explica que o seu movimento de transformação perpassou vários aspectos. 0 autor ressalta as duas naturezas do ser humano: a natureza biológica e a natureza social. A primeira - natureza biológica - tem a ver com aspectos e traços que fazem do homem o sujeito humano, mas que, para isso, necessita da segunda - natureza social - que tem a ver com as relações sociais existentes entre ele e os sujeitos ao seu redor, a interação entre ele e o mundo objetivo.

Para a Teoria Histórico-Cultural, o processo de humanização está na relação dialética entre o biológico e o cultural. Acerca disso, ao se referir à essência de cada uma dessas naturezas, Leontiev (1978) explica que cumpre a cada sujeito aprender a ser homem, pois apenas 0 aspecto biológico não é decisivo para que sejamos humanos. Unicamente as condições oferecidas pela natureza (biológico) não são suficientes para se viver em meio aos outros sujeitos. "0 homem não está evidentemente subtraído ao campo da ação das leis biológicas. 0 que é verdade é que as modificações biológicas hereditárias não determinam o desenvolvimento sócio-histórico do homem e da humanidade" (LEONTIEV, 1978, p. 264).

Nesse processo de humanização, as relações sociais se fazem essenciais. É por meio da interação do homem com os demais e, consequentemente, com a apropriação da cultura em que está inserido, que ocorre o desenvolvimento. 0 homem, desde seu nascimento, precisou criar meios e métodos de sobrevivência. Ao longo do tempo, os procedimentos e as estratégias deixadas por seus 
ancestrais já não eram suficientes para garantir a sua permanência no mundo, logo, à medida que surgiam novas demandas, novos modos de atendê-las iam sendo criados.

As necessidades humanas desencadeiam novas qualidades no ser humano, sendo que, originalmente biológicas, se transformam em histórico-culturais (MORETTI, ASBAHR, RIGON, 2011,). Inicialmente eram biológicas e produto de instinto de sobrevivência do homem, que, com o passar do tempo, foi internalizando mais sobre o meio em que vivia e isso acabou agregando novas formas de pensar. Ao fazer parte desse processo e vivenciar a partir de suas experiências as contribuições de outros, o homem torna-se humano.

Segundo Pino (2005), uma hipótese plausível a respeito da experiência cultural da humanidade é que sua evolução tem relação com a experiência cultural dos povos, na qual, as marcas da cultura herdada dos ancestrais estão presentes no movimento da evolução da espécie. Diante disso, entendemos que as contribuições deixadas por seus antepassados e os novos meios de solução para seus anseios e vontades colaboraram para a constituição dos seres humano, tal como se encontram hoje. Pois, ao buscar formas de satisfação, passa a ter como propósito assegurar não apenas os fatores biológicos de sua existência, mas, sobretudo, aqueles associados à apropriação de sua cultura, ou seja, novos hábitos, crenças e conhecimentos. Assim, por meio das suas necessidades, ao agir de maneira proposital sobre a natureza, o homem deixa as marcas da atividade humana (MORETTI, ASBAHR, RIGON, 2011), se transformando e constituindo-se humano.

Nesta lógica, os modos de sobrevivência que o homem é capaz de desempenhar na sociedade é uma das diferenças entre ele e os animais. A distinção está presente nas capacidades que ambos conseguem realizar. Segundo Pasqualini (2016), para Vigotski a conduta do animal é determinada pelo estímulo do ambiente, diferindo do psiquismo humano, que tem a capacidade de dominar 0 próprio comportamento.

Também o trabalho é responsável pela apropriação da cultura. Este fator característico da espécie humana é fruto da colaboração e da comunicação, fazendo parte das relações sociais. 0 homem difere-se da natureza e satisfaz suas necessidades por meio dela. Mas ele só consegue isso, ao adquirir os conhecimentos passados pelas gerações anteriores graças à interação com outros sujeitos, o que promove 0 desenvolvimento das funções psicológicas superiores, que são unicamente humanas. Assim,

Todas as funções psicointelectuais superiores aparecem duas vezes no decurso do desenvolvimento intelectual da criança: a primeira vez, nas atividades coletivas, nas atividades sociais, ou seja, como funções interpsíquicas: a segunda, nas atividades individuais, como propriedades internas do pensamento da criança, ou seja, como funções intrapsíquicas (VIGOSTSKI, 2014, p. 114, grifo no original)

As funções psicológicas superiores contêm os caminhos históricos percorridos pela humanidade e os produtos obtidos através da interação com os outros sujeitos. Desta maneira, partem de ações realizadas no coletivo para as ações pessoais, ou seja, vão do social para o individual, do nível interpsíquico para o intrapsíquico. As funções psíquicas são estabelecidas fundamentadas na relação entre os sujeitos e o meio em que estão adentrados através da aprendizagem, atividade tipicamente humana

Essa ideia é confirmada por Núñes (2009), ao explicar que a aprendizagem tem caráter social, decorre da interação, da colaboração e da comunicação entre as pessoas, e seu caráter social "significa que, na etapa inicial, existe um caráter interpsicológico como atividade conjunta. E no próprio processo de assimilação internaliza, passando ao plano intrapsicológico" (NÚÑ̃ES, 2009, p. 26). 
No processo de internalização, os conhecimentos elaborados historicamente promovem 0 desenvolvimento do sujeito, uma vez que eles consolidam a cultura humana. É neste contexto que podemos compreender a importância da matemática como produto cultural, como síntese histórica, advinda da interação entre sujeitos na busca pela satisfação de suas necessidades, cuja apropriação contribui para o desenvolvimento dos sujeitos, na perspectiva da humanização.

Todavia, não é qualquer conhecimento que proporciona isso. Autores como Davidov (1982) e Rubtsov (1996) se referem a dois tipos de pensamento que permitem ao sujeito abordar a realidade e que correspondem, respectivamente, a dois tipos de conhecimentos: 0 empírico e 0 teórico. 0 pensamento empírico é o resultado da relação direta com a realidade. Já o pensamento teórico

\begin{abstract}
constituye una idealización del aspecto fundamental de la actividad prática-objetiva, a saber, de la reproducción en ella de las formas generales de las cosas, de su medida y de sus leyes. Esta reproducción tiene lugar en la actividad laboral como em um singular experimento senorio-objetivo. Luego, ese experimento va adquiriendo cada vez más un carácter cognoscitivo, permitiendo que el hombre pase con el tiempo a experimentos mentales, atribuya mentalmente a los objetos uma u otra interacción, determinada forma de movimento (DAVIDOV, 1982, p. 299-300).
\end{abstract}

Por seu caráter cognitivo, o conhecimento teórico viabiliza reproduzir as formas gerais do movimento perpassado pela humanidade, contemplando a sua gênese. Daí sua importância, pois permite que 0 ser humano se aproprie do processo lógico - histórico do conceito e crie novas capacidades psíquicas superiores. Em paralelo, temos também os empíricos, que possuem como característica principal a representação e a comparação entre os fenômenos. Ao deixar que sejam comparados, os empíricos são apreendidos por meio da observação, da representação e pela atribuição de juízos. Com isso, o sujeito, ao se apossar de conceitos, também realiza generalizações, embora elas não representem, em sua essência, o conceito. Assim, ainda que se admita a importância de ambos, é 0 teórico que tem predomínio e potencializa o processo de aprendizagem, é o teórico que ativa as mais complexas funcionalidades mentais.

Estabelecendo conexões com o conhecimento matemático, vislumbramos um caminho orientado do empírico ao teórico, de relações estritamente sensitivas a generalizações complexas. Indo além de aspectos sensoriais, Moura (2011, p. 53) destaca que a matemática deve "ser aprendida como parte del desarrollo de la humanidad en su dinámica de solución de problemas generados por las necesidades de la creación de instrumentos que amplían la capacidad corporal de los hombres". Os instrumentos, oriundos de necessidades sociais, foram elaborados ao longo do tempo, e seu constante aperfeiçoamento exigiu do ser humano a produção de conhecimentos, como expressa Boyer (1974, p. 1), ao afirmar que "a persistência da raça humana tem relação com o desenvolvimento no homem de conceitos matemáticos". A matemática, como ferramenta simbólica, instrumentalizou o homem no avanço em busca do conhecimento teórico que Ihe permitiu aprimorar a vida na direção da segurança e do conforto.

As experiências cotidianas com o meio e a relação com a natureza originaram e mobilizaram a produção da matemática, a partir de questões referentes a caça e pesca, alimentação dos animais e observação dos fenômenos regulares, chegando às sínteses matemáticas tais como as conhecemos hoje. A satisfação dessas necessidades ao longo do processo histórico da humanidade exigiu soluções cada vez mais precisas, levando à criação de mais sistematizações, que, para 
serem perpetuadas, precisavam ser passadas para as próximas gerações. Esse processo deu origem à educação escolar, sendo escolhido aquilo que é considerado mais relevante para ser ensinado, que se materializa em forma de conteúdo escolar.

Mas aí surge um novo desafio: encontrar modos de ensinar esses conteúdos de forma que todos tenham possibilidades de utilizá-los como ferramentas psicológicas de desenvolvimento.

Estabelecendo relações entre as origens dos conceitos matemáticos, concebidos como advindos de um movimento lógico-histórico, e aspectos associados à apropriação da cultura por meio das relações sociais, pautado pela Teoria Histórico- Cultural, um dos caminhos relacionados ao ensino e à aprendizagem da matemática é a Atividade Orientadora de Ensino (AOE), proposta por Moura (1996, 2010). Constitui-se como uma unidade entre a atividade de ensino do professor e a de aprendizagem do aluno, respaldando as ações do professor na organização do ensino, entendido como um processo educativo. Objetiva a modificação do psiquismo do estudante que está em processo de aprendizagem, proporcionando-Ihe as aquisições culturais - mediante conteúdos escolares aprendidos - rumo a um processo de humanização. Isso posto, a AOE, ao se preocupar, no processo, com o professor e com o estudante, se caracteriza como teórica e metodológica.

Segundo Moura (2001), a Atividade Orientadora de Ensino tem presente em sua estrutura ações que viabilizam a interação entre os sujeitos, mediadas por um conteúdo por meio de negociação de significados, com o objetivo de solucionar uma situação-problema. Nesta perspectiva,

A atividade orientadora de ensino tem uma necessidade: ensinar; tem ações: define o modo ou procedimentos de como colocar os conhecimentos em jogo no espaço educativo; e elege instrumentos auxiliares de ensino: os recursos metodológicos adequados a cada objetivo e ação (livro, giz, computador, ábaco etc). E por fim, os processos de análise e síntese, ao longo da atividade, são momentos de avaliação permanente para quem ensina e aprende. (MOURA, 2001, p. 155)

Ela é uma proposta de organização do ensino e da aprendizagem e se configura como uma possibilidade de realizar a atividade educativa, tendo como base o conhecimento produzido sobre os processos humanos de construção de conhecimento (MOURA et al., 2010). A AOE fundamenta-se de acordo com a estrutura da atividade proposta por Leontiev (1978) e realiza-se por meio de finalidades - ensinar e aprender - e de ações, que levam em conta condições objetivas da escola (MOURA et al., 2010).

Ademais, as ações são organizadas e planejadas pelo professor, tendo em mente o movimento lógico-histórico do conceito. As correlações entre o lógico e o histórico, para Kopnin (1978), referem-se ao pensamento e à constituição do objeto em sua história. 0 histórico pressupõe o processo de transformação, surgimento e desenvolvimento do objeto, "atua como objeto do pensamento, 0 reflexo do histórico, como conteúdo. 0 pensamento visa à reprodução do processo histórico real em toda a sua objetividade, complexidade e contrariedade" (KOPNIN, 1978, p. 183). 0 meio pelo qual 0 pensamento realiza a tarefa é denominado por Kopnin (1978) de lógico. Para esse autor, o lógico é reflexo do histórico, é a representação da essência do objeto em sua história.

Colocar-se em situações que contemplem a gênese de um conceito, derivada de seu movimento lógico-histórico, oportuniza aos estudantes se apropriarem do movimento humano que foi necessário para a sua formação, pois leva em consideração as necessidades que culminaram no seu surgimento, contribuindo para a compreensão de que este não está pronto e acabado. Compreender 
0 aspecto lógico- histórico de um determinado conceito possibilita refletir sobre o movimento de formação dos conceitos matemáticos vistos hoje em dia, suas respostas para problemas objetivos passados e atuais.

A AOE orienta as ações do professor que são elaboradas a partir dos objetivos e das estratégias propostos por ele em relação ao que almeja trabalhar. Segundo Moura (1996, p. 32), essa proposta "contém elementos que permitem à criança apropriar-se do conhecimento como um problema. E isto significa assumir 0 ato de aprender como significativo tanto do ponto de vista psicológico, quanto de sua utilidade". A intencionalidade do professor neste fundamento teórico-metodológico tem um papel essencial na organização do ensino. Ao se constituir como uma forma de ação que busca o ensino e aprendizagem dos estudantes, toma a dimensão de mediação entre o professor e 0 estudante (MOURA et al., 2010), sendo que ambos se transformam e se fazem sujeitos de qualidade nova.

Em sua estrutura metodológica, a AOE pressupõe três elementos: síntese histórica do conceito; situação desencadeadora de aprendizagem - SDA, que contém um problema desencadeador de aprendizagem; e síntese da solução coletiva.

A síntese histórica do conceito exige que o professor estude o movimento lógico-histórico do conceito a ser trabalhado. Na perspectiva da AOE, compreendendo que os conceitos matemáticos tiveram ascendência nas necessidades da humanidade, é fundamental que o professor conheça como se deu a evolução desse conceito ao longo dos anos e, especificamente a natureza de sua origem.

Em vista disso, entendido como produção humana, o conceito é algo histórico, cultural. A dimensão histórica do conceito na AOE é uma das formas de se perceber o seu processo sociocultural (CEDRO, 2004), no qual a síntese histórica deve envolver tanto o seu aspecto pedagógico quanto 0 seu contributo social.

A situação desencadeadora de aprendizagem expõe um problema, impulsionador de aprendizagem e deve ser organizada pelo professor com vistas a abarcar a essência do movimento lógico-histórico e a mobilizar a problemática humana que levou a criação desse conceito. Assim organizada, ela proporciona ao estudante 0 movimento de apropriação do conceito, estimulando-o a solucionar o problema de forma coletiva, promovendo, então, a sua aprendizagem. Segundo Moura e Lanner de Moura (1998), os jogos, as situações emergentes do cotidiano e a história virtual são instrumentos metodológicos que se configuram como situações desencadeadoras.

Para esses autores, o jogo, como apoio no processo de ensino e aprendizagem, preserva o caráter de problema e coloca o estudante diante de uma situação similar à vivenciada pelo homem no percurso histórico dos conceitos matemáticos. As situações emergentes do cotidiano permitem ao aluno vivenciar problemas cotidianos que tragam a ele significados do conceito que está sendo trabalhado. Já a história virtual do conceito, também intenciona colocar o estudante perante uma situação genérica vivenciada pelo homem. Portanto, podemos verificar que as estratégias utilizadas na organização de uma situação desencadeadora objetivam, de forma lúdica, colocar as crianças em situações de construção de um conhecimento a partir do compartilhamento de significados.

A história virtual não se refere apenas aos meios digitais, mas constitui-se de situações-problema que envolvem personagens infantis ou lendas da própria história da matemática como instigadoras do pensamento do estudante (LOPES, VAZ, 2014). Assim, a história virtual pode ser apresentada aos estudantes por intermédio de vídeos, cartas, teatros, entre outros. Nesta perspectiva, ao planejar e organizar uma SDA, ela deve ter o potencial de provocar o surgimento do motivo da aprendizagem no estudante (MOURA et al., 2018), para que culmine na apropriação do conceito. 
A síntese da solução coletiva diz respeito à solução matemática encontrada pelo grupo para 0 problema proposto, ressaltando que este deve ser um processo em que uns compartilhem com os outros as suas ideias, as hipóteses e as possíveis soluções. Por isso, a organização de uma situação desencadeadora de aprendizagem deve propiciar aos estudantes a interação entre eles, a fim de promover a aprendizagem do conceito.

Tomando como pressuposto 0 que até aqui foi exposto, ao compreender que a apropriação da cultura e as relações sociais são essenciais no processo de humanização; que é a escola o espaço de aprendizagem responsável por estabelecer de maneira intencional um ensino que promova 0 aprimoramento das funções psíquicas dos estudantes; e que a matemática é um elemento cultural constituído historicamente; realizamos um estudo embasado em situações desencadeadoras de aprendizagem relacionadas aos conceitos de volume e capacidade para uma turma dos anos iniciais do Ensino Fundamental.

A seguir apresentamos os caminhos metodológicos da pesquisa, discorrendo sobre as etapas de realização das ações e sobre os aspectos do projeto no âmbito do qual a pesquisa foi realizada.

\section{CAMINHOS METODOLÓGICOS}

Ao realizar uma pesquisa, buscamos entender os questionamentos e os anseios em relação a alguma dada circunstância. Partindo da perspectiva da Teoria Histórico-Cultural de que 0 sujeito se constitui por meio das relações sociais e da apropriação da cultura, pesquisar em Educação significa investigar os aspectos conectados ao processo de humanização do homem, os questionamentos relacionados ao desenvolvimento humano e da sociedade (CEDRO, NASCIMENTO, 2017).

Neste movimento de procurar possíveis respostas acerca do processo de ensino e aprendizagem da matemática, orientamo-nos pela seguinte questão: é possível organizar situações desencadeadoras de aprendizagem de sorte que alunos dos anos iniciais se aproximem dos conceitos de volume e capacidade? Uma vez que é papel da escola se centrar na aprendizagem dos estudantes e promover novas consolidações de funções psicológicas superiores - 0 que pode ser concretizado na formação do pensamento teórico (DAVIDOV, 1988) por meio da intencionalidade do professor na organização do ensino -, nosso objetivo na pesquisa discorrida neste artigo foi identificar indícios de aprendizagem sobre volume e capacidade a partir de uma situação desencadeadora de aprendizagem, na perspectiva da Atividade Orientadora de Ensino, nos anos iniciais do Ensino Fundamental.

Consoante a isso, embora os nossos estudos foram anteriores a publicação da Base Nacional Comum Curricular (BNCC), entendemos que estão coerentes com o que está apresentado no documento norteador educacional atual. Sendo assim, ao elencar a habilidade "reconhecer volume como grandeza associada a sólidos geométricos e medir volume por meio de empilhamento de cubos, utilizando, preferencialmente objetos concretos" (BRASIL, 2017, p. 297), nos direcionamos aos encaminhamentos realizados - estudo e organização de situações que envolvessem essas grandezas.

As ações que são aqui relatadas foram planejadas e realizadas por integrantes do projeto Clube de Matemática (CluMat) da Universidade Federal de Santa Maria (UFSM), que tem como foco o ensino e a aprendizagem de matemática nos anos iniciais do Ensino Fundamental, e a preocupação voltada à formaç̧ão do professor, do futuro professor e dos estudantes da Educação Básica. Iniciando suas ações em 2009, o principal objetivo do projeto é envolver os sujeitos participantes num movimento de discussão sobre a organização do ensino de matemática. Formado por acadêmicos dos cursos de Licenciatura em Pedagogia, Educação Especial e Matemática, estudantes da 
pós-graduação, professores do Ensino Superior e professores da Educação Básica, o projeto tem como premissa estabelecer uma interação entre universidade e escola.

0 Clube de Matemática oferece ações de estudos relacionados aos aspectos teóricos e metodológicos do ensino de matemática, além de planejar, desenvolver e avaliar ações de ensino nas escolas públicas parceiras com alunos dos anos iniciais do Ensino Fundamental. Sua organização acontece em dois momentos: o primeiro ocorre em encontros semanais na universidade, quando os participantes elencam conteúdos matemáticos que irão trabalhar, realizam estudos teóricos e metodológicos sobre o conteúdo, planejam as atividades e organizam ou constroem materiais de apoio; já o segundo momento contempla as ações que foram planejadas e organizadas pelos participantes e que são concretizadas uma vez por semana na escola.

Pautados nessa organização, os participantes do projeto no decorrer do segundo semestre do ano de 2017, realizaram estudos sobre os conceitos de volume e capacidade em de referências de matemática e história da matemática, como Bendick (1965), Eves (1997) e Silva (2010). 0 intuito era identificar na história da humanidade indicativos da constituição lógico-histórica destes conceitos, necessidades e processos que mobilizaram sua criação, concernente a outros nexos conceituais. A partir daí foram organizadas e realizadas ações na escola.

$\mathrm{Na}$ impossibilidade de discorrer sobre todo o processo, neste artigo nos ateremos a nosso estudo investigativo, de natureza qualitativa, nas ações realizadas pelas futuras professoras e pela professora regente participantes do projeto num total de 04 encontros em uma turma de $4 .{ }^{\circ}$ ano do Ensino Fundamental, composta por 17 alunos, em uma escola pública do município de XXX, na expectativa de identificar indícios de aprendizagem dos estudantes. Os participantes tinham, no momento do trabalho, idade média de 09 anos e estudavam no turno matutino, mesmo período em que ocorrem as ações do CluMat

As inquietações que mobilizaram este trabalho se enquadram nos processos investigativos ancorados na Teoria Histórico-Cultural, pois envolvem o estudo de um objeto que tem seu nascedouro em um motivo não apenas individual, mas assentado em uma necessidade social (ARAUJO; MORAES, 2017). Logo, além de esse trabalho buscar indícios de aprendizagem dos conceitos de volume e capacidade pelos estudantes, também trará contributivos para os processos coletivos futuros de organização do ensino desses conceitos.

Para a produção de dados, todos os momentos foram gravados em áudio e vídeo, bem como registrados em fotos, além de serem utilizados os registros dos estudantes. As falas deles durante as ações foram transcritas e embasaram o processo analítico. Atendendo às recomendações do Comitê de Ética em Pesquisa de nossa instituição (CEP/UFSM), para preservar a identidade dos estudantes, foram usados nomes fictícios.

\section{O MOVIMENTO DE ENSINO E APRENDIZAGEM SOBRE VOLUME E CAPACIDADE}

Como já exposto, entendemos a matemática como produto histórico e cultural, oriunda de necessidades advindas ao longo da história da humanidade. Seu desenvolvimento permitiu criar novas capacidades psicológicas no ser humano e, consequentemente, novas qualidades de vida. Atualmente existe uma gama de conhecimentos matemáticos importantes para serem aprendidos como forma de os sujeitos se inserirem no âmbito social. Alguns deles pelo convívio e pelas relações diretas com o cotidiano. Todavia, outros, mais complexos, precisam de processos que coloquem o sujeito em situações que exijam, mais que deduções diretas, processos mentais mais elaborados e que não 
acontecerão espontaneamente. Estes, que conduzem ao desenvolvimento do pensamento teórico (DAVIDOV, 1982), são, em especial, de responsabilidade da escola e implicam uma organização intencional do ensino.

Ao nos referirmos à intencionalidade da organização do ensino, queremos dizer, tal qual nos coloca Vigotski (2000), que não é qualquer ensino que promove a aprendizagem e o desenvolvimento. É preciso que o objeto da atividade docente seja levar os alunos a se apropriarem do conhecimento, 0 que deve estar expresso nas ações que realiza. Sendo assim, em um primeiro momento, é relevante que o professor compreenda o movimento lógico-histórico do conceito para, então, organizar situações desencadeadoras de aprendizagem que contemplem a essência do conceito matemático a ser trabalhado. Em outras palavras, ele precisa ter conhecimento do seu objeto de ensino, a fim de organizá-lo para, da melhor maneira possível, propiciar o desenvolvimento do pensamento teórico dos educandos.

No processo de construção do nosso trabalho, como embasamento teórico, entende-se como volume, de acordo com Lima (1991), a quantidade de espaço que um determinado sólido ocupa, sendo que para medir a grandeza volume é necessária compará-la com uma unidade estabelecida como padrão e o resultado dessa comparação será a medida do volume. Também é importante ressaltar que qualquer objeto pode se decomposto em partes cujo volume se conhece, de modo que a soma dos valores destas partes revela o volume total do objeto.

Já a grandeza capacidade pode ser definida, segundo Bendick (1965) como a quantidade que um recipiente pode conter, ou seja, a capacidade é quanto "entra" ou "cabe" em um recipiente ou objeto (podemos nos referir a materiais sólidos como grãos, ou líquidos como água, ou mesmo gasosos, como oxigênio e para tanto podemos usar inclusive diferentes unidades de medida de capacidade). De forma usual, também entendemos a capacidade como o volume interno de um objeto.

Uma relação matemática importante entre essas duas grandezas nos diz que em uma caixa com forma de cubo cuja aresta mede $1 \mathrm{dm}$, cabe exatamente 1 litro de água; ou seja $1 \mathrm{dm}^{3}=1 \mathrm{I}$. Embora seja possível estabelecer essa relação, é importante destacar que conceito de volume está vinculado à geometria espacial, ou seja, envolve três dimensões. Esse fato é essencial no estudo dos múltiplos e submúltiplos das unidades fundamentais dessas grandezas (volume = metro cúbico e capacidade $=$ litro), assim como na compreensão dos cálculos de transformação dessas unidades e nos processos de leitura e escrita das medidas

Isso posto, sem detalharmos muito aqui neste recorte, o primeiro momento foi de estudo sobre os conceitos de capacidade e volume, incluindo leituras, debates e vivência de situações, por parte dos professores e futuros professores que participam do projeto. Posteriormente, de forma coletiva, foram discutidas possibilidades para a realização de ações que viessem a ser situações desencadeadoras de aprendizagem e, também, maneiras para mobilizar os estudantes rumo à aprendizagem dos conceitos com os quais queríamos trabalhar.

Daí em diante, foram elaboradas situações que se aproximam do que Moura e Lanner de Moura (1998) denominam de situações emergentes do cotidiano, ou seja, situações que emergem do espaço em que estão inseridos os estudantes e do material com que já possuem contato. No nosso caso, partimos do processo de construção de caixas com papel-cartão, usuais nas ações do dia a dia para guardar materiais diversos. A intenção era aproximar os estudantes do movimento humano que partiu da observação e da comparação do conhecido - antes a natureza; agora, o objeto humano caixinha - para chegar à padronização derivada da necessidade de sistematizar e formalizar o conhecimento, a fim de que ele pudesse ser acessível a outros sujeitos. 
A SDA proposta, que partiu das caixinhas de papel-cartão, efetivou-se orientada por três questionamentos:

- Como podemos descobrir qual das caixinhas é a maior?

- Como fazer para sabermos, de forma mais exata possível, qual é a caixinha que tem maior capacidade? - De que forma podemos descobrir qual é o volume do cubinho?

Para isso, a turma foi dividida em grupos, os quais receberam conjuntos iguais de cinco caixinhas de tamanhos e cores diferentes. Embora a organização fosse em grupos, as discussões que apresentamos se referem ao momento da síntese coletiva, quando foram apresentadas e debatidas as soluções encontradas.

a) Como podemos descobrir qual das caixinhas é a maior?

A questão foi apresentada aos alunos com a intenção de promover uma discussão sobre as grandezas associadas a um determinado objeto. Inicialmente eles manipularam as caixinhas, colocando-as umas próximas das outras, rotacionando-as, mudando-as de lugar, comparando-as para encontrar uma resposta à problematização.

Quadro 1 - Primeira questão orientadora da SDA

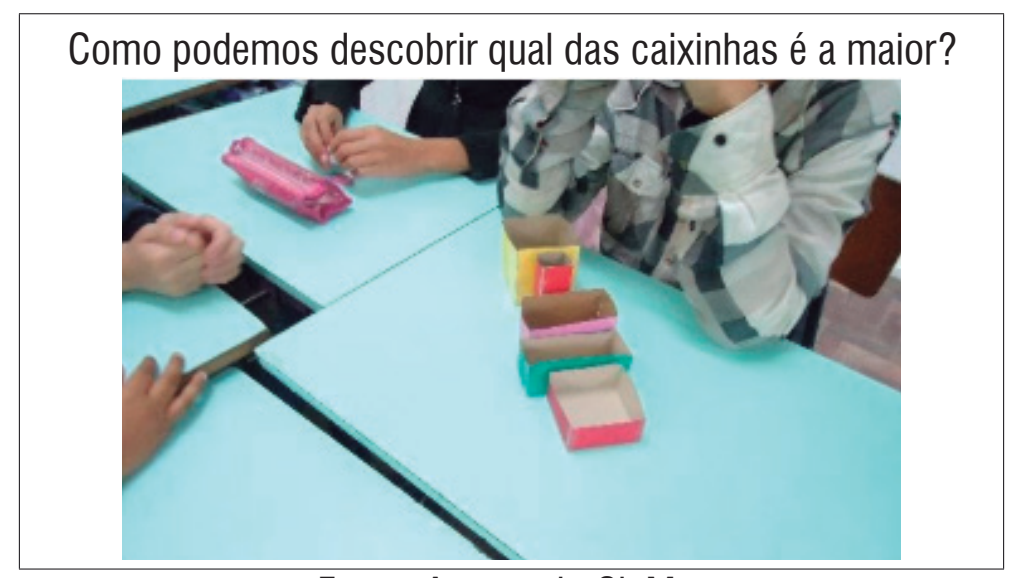

Fonte: Acervo do CluMat

Depois de algum tempo de manuseio, muitas hipóteses foram levantadas: "A caixinha amarela é a maior, podemos enxergar", dizia Manuela referindo-se à altura da caixinha, mas o seu colega, Augusto, discordava, afirmando que a verde era maior, mostrando o comprimento da base dela. Enquanto isso, outros colegas realizavam a sobreposição das caixinhas, levando Pedro a dizer que a " $A$ caixinha rosa mesmo que é mais baixa, é a maior de todas", mostrando a superfície da base.

Os diálogos entre os estudantes possibilitam perceber que, ao analisar qual objeto seria "maior", eles estabeleceram diferentes critérios para obter a resposta do problema desejado. Tais critérios estão relacionadas a grandezas passíveis de mensuração, as quais, ao serem exploradas, ampliam as chances de compreensão do conceito de medida, intrinsicamente associado ao de volume e capacidade, com o qual queríamos trabalhar. Lembrando que

a grandeza pode ser definida como uma qualidade de um objeto, ou fenômeno, que pode ser quantificada. Uma qualidade de um objeto, ou fenômeno pode ser 
entendida como o conjunto de relações que estabelecemos entre estes objetos, ou fenômenos. Assim, a percepção de uma qualidade é sempre relativa a algo, fruto de comparação e identificação. (MOURA et al., 2018, p. 5. grifo dos autores)

Continuamos as discussões no sentido de que os alunos compreendessem que, indicar o que é "maior" ou "menor" implica identificar a qual grandeza estamos nos referindo. E, definida a grandeza, a comparação permite chegar a uma conclusão. Ao propormos colocar todas as caixas com a parte aberta para cima, os alunos apontaram algumas conclusões: é só comparar as caixas colocando uma ao lado da outra; a amarela é a "mais alta" (maior em altura) e a verde é a "mais larga" (maior em largura).

Esse processo de encaminhamento e discussão realizado pelos alunos coincide com o processo histórico de determinação de medidas que, inicialmente, não exigia exatidão e era estabelecido por comparações que levavam à definição do que era maior, menor ou igual, o que satisfazia necessidades imediatas.

0 homem primitivo não necessitava de um sistema de medidas muito elaborado. Suas necessidades metrológicas certamente eram apenas para algumas indicações rústicas de posições, distâncias aproximadas e relações de grandezas como "maior do que" e "menor do que". (SILVA, 2010, p. 38)

A solução encontrada de "medir" por comparação entre as caixinhas os seus diversos comprimentos, naquele momento, bastou aos alunos, uma vez que chegaram à resposta para o problema proposto, embora essa não fosse a única.

b) Como fazer para sabermos, de forma mais exata possível, qual é a caixinha que tem maior capacidade?

A partir da verificação de qual caixinha seria a "maior" levando em consideração as qualidades selecionadas, passamos a um novo questionamento relacionado, então, à capacidade das caixinhas. 0 propósito era discutir que as grandezas podem admitir uma variação segundo uma quantidade, que pode ser expressa em valores numéricos, mas que, para tanto, faz-se necessário determinar os padrões para a comunicação do resultado. Ademais, queríamos nos aproximar dos conceitos de volume e capacidade.

Apresentada a situação, foi discutido o que significava "ter maior capacidade", e a resposta aceita por todos era que significava "caber mais". Daí, as primeiras hipóteses levantadas se referiram a utilizar objetos que os alunos tinham consigo para preencher o espaço das caixinhas, como, por exemplo, borracha e giz. Todavia, alguns deles observaram que, se cada um utilizasse um material diferente, os valores também seriam distintos, portanto precisariam de algo comum a todos. Essa discussão nos remete a questões relativas à necessidade de padronização de unidades de medida, situação que percorreu um longo processo até chegar ao que temos hoje.

Miguel se lembrou do material dourado que havia na sala e sugeriu que eles poderiam utilizar os cubinhos para preencher 0 espaço do interior das caixinhas. A solução de preencher com cubinhos permitiu a aproximação com o conceito de volume, pois, ao determinar o valor numérico em "quantidade de cubinhos", estamos determinando o volume ocupado por aqueles cubinhos dentro das caixas. Essa solução também se aproxima de uma definição usual para capacidade, permitindo a sua exploração como 0 volume interno de um objeto.

Além disso, os cubinhos se configuraram como um material eficiente para a proposta, tendo em vista a manutenção das características que o definem como unidade, já que todas as peças têm mesmo formato e tamanho, o que não estaria garantido com a utilização de borrachas e giz. 
Quadro 2 - Segunda questão orientadora da SDA

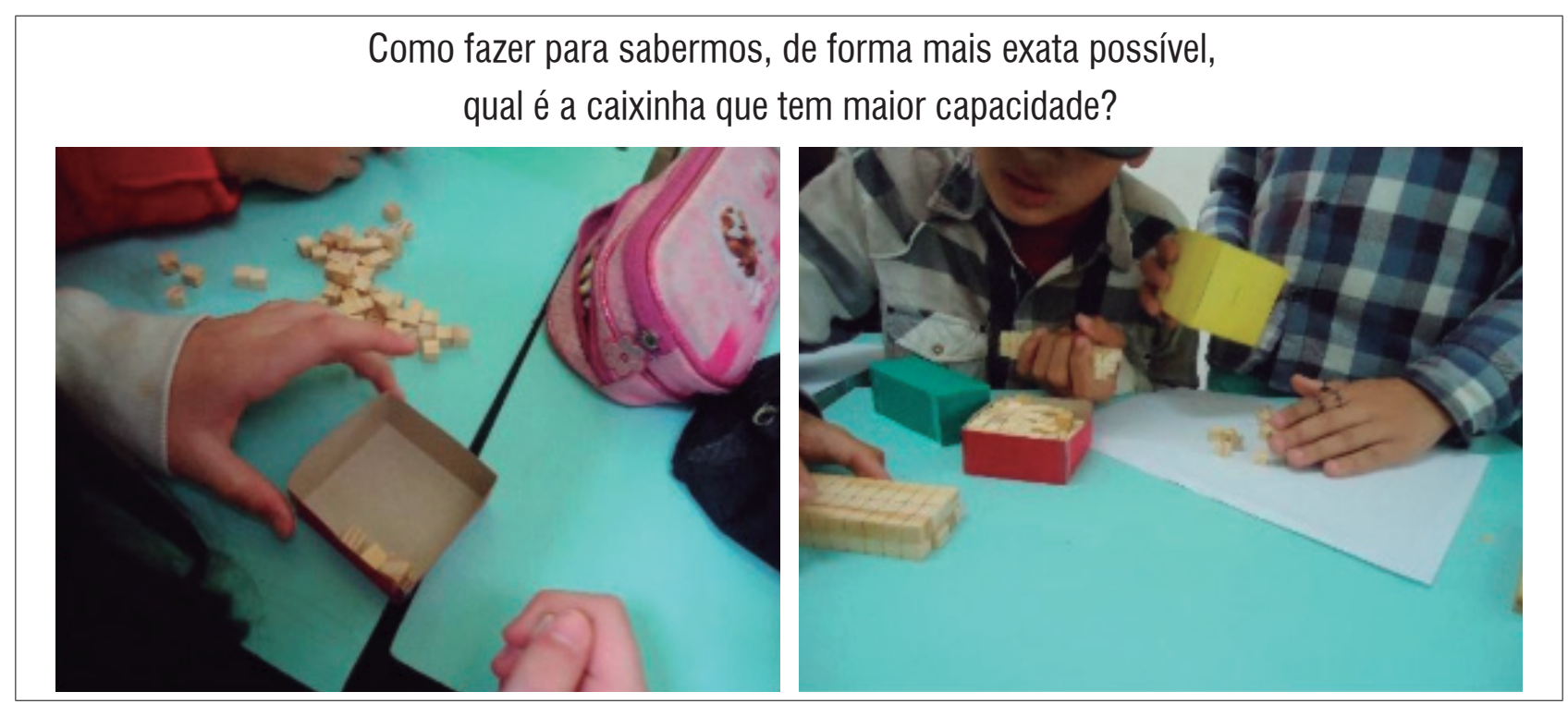

Fonte: Acervo do CluMat

Diferentes modos foram encontrados para solucionar o problema. Carol explicou que: "fomos enchendo as caixinhas e contando os cubinhos que a gente ia colocando até ficar cheia". Eric contou que "nós forramos o fundo da caixinha, depois forramos o resto e aí calculamos, por exemplo, na caixinha verde cabia 21, aí contamos, 21 mais 21, mais 21, mais 21". Já Augusto explicou da seguinte forma a organização do grupo: "forramos a base da caixinha com cubinhos e percebemos que não precisaria preencher toda a caixinha, apenas fazer mais um 'murinho', multiplicando assim, o que tinha no chão [referindo-se à base] vezes esses cubinhos" [mostrando a altura].

É possível perceber, pelas manifestações dos alunos, os diferentes níveis de solução dados para o problema: 0 grupo da Carol fez por contagem de um em um; 0 do Eric, por agrupamento, e 0 do Augusto, pelo uso da multiplicação, aproximando-se, de um modo geral, da fórmula atualmente conhecida para 0 cálculo de volume de um paralelepípedo. Tais níveis coincidem com indicativos dos processos percorridos pela humanidade para chegar à sistematização do conceito que temos atualmente de volume e capacidade, na medida em que algumas soluções são totalmente sensoriais (preencher toda a caixa para saber quantos cabem), enquanto outras recorrem a recursos matemáticos (a partir de alguns dados é possível calcular sem preencher a caixinha toda).

Destacamos a relação entre as medidas de comprimento trazidas pelo grupo de Augusto. Conforme afirma Crease (2013, p. 137), muito antes de serem estabelecidas a fórmula e a compreensão dessa grandeza, já se tinha o entendimento de que "medidas de volume podiam ser formadas a partir das medidas de comprimento". Ou seja, o grupo fez uso da medida de comprimento de cada uma das arestas para estimar quanto caberia em cada caixinha, embora ainda comparando sensorialmente com preenchimento da caixinha.

Acompanhando a discussão coletiva e analisando a organização do material discreto utilizado pelos alunos, podemos inferir que eles se aproximaram do conceito, com ideias como considerar 0 
espaço todo e, também, as três dimensões de comprimento. Porém, após os registros de quantas unidades ocupariam 0 espaço de cada caixinha, os alunos perceberam que o resultado final tinha sido distinto e Amanda se manifestou, deduzindo que "mesmo organizando de formas diferentes, se as caixinhas das mesmas cores tinham o mesmo tamanho [conforme tinham comparado anteriormente] a quantidade de cubinhos deveria ser a mesma para todo mundo". Todos concordaram, 0 que acarretou um novo diálogo para descobrir o que havia acontecido.

A manifestação de que, tendo o mesmo espaço, porém com organizações diferentes, o resultado precisa ser idêntico, aproxima-se do Princípio de Cavalieri, que Eves (2014, p. 246) descreve da seguinte maneira: "Se dois sólidos são tais que todo plano decante a eles e paralelo a um plano dado determina nos sólidos secções cuja razão é constante, então a razão entre os volumes desses sólidos é a mesma constante". Sabemos que, nesse caso, os sólidos não foram subdivididos por secções formando linhas paralelas, todavia, ao perceber que essas subdivisões se consolidariam na organização do material discreto, podemos identificar que os estudantes supuseram que o volume não se modificaria, mesmo tendo essas diferenças.

Após a discussão, os alunos concluíram que alguns grupos não haviam preenchido corretamente a caixinha, deixando espaços, além do que havia problemas com o material, pois nem todos os cubinhos eram exatamente iguais, por possíveis problemas de fabricação, o que os levou a perceber 0 caráter subjetivo da medida. Ao optarem pela utilização dos cubinhos para encontrar a capacidade da caixinha, a turma encaminhou, de forma natural, as discussões e as sínteses coletivas do problema apresentado para a busca de um volume interno daquele objeto, visualizando essa relação tênue entre as duas grandezas.

A partir daí, passamos a discutir o que representaria o espaço ocupado pelos cubinhos, sendo apresentado para eles a palavra volume, grandeza que representaria quanto espaço um objeto ocupa. Para deduzir a relação com o material que estavam usando até o momento, repercutimos a pergunta anterior, porém agora, questionando: "qual é o volume ocupado pelos cubinhos que preencheram cada uma das caixinhas?"

As repostas reportaram à quantidade de cubinhos. Contudo, a unidade padrão do volume não é o material discreto (cubinho). Para discutir sobre isso, foi apresentada outra questão que visava à aproximação da universalização das unidades de medida:

\section{c) De que forma podemos descobrir qual é o volume do cubinho?}

Com o nosso questionamento seguinte, queríamos complementar o que havia sido discutido anteriormente no tocante à possibilidade de expressar a variação das grandezas de forma numérica por uma unidade de medida, no sentido de considerar que existe uma padronização que facilita a comunicação desses valores de modo a que todos compreendam.

Assim, tendo em vista que a grandeza volume possui unidade e subunidades padrão, lançamos 0 questionamento com o propósito de que os alunos conseguissem estabelecer a relação entre 0 material discreto (cubinho) e a medida padrão $\left(\mathrm{cm}^{3}=1 \mathrm{~cm} \times 1 \mathrm{~cm} \times 1 \mathrm{~cm}\right)$. Para mais, vislumbrávamos a possibilidade de sistematizar o que eles já haviam apontado anteriormente em relação ao modo matemático de calcular o volume de um paralelepípedo. 
Quadro 3 - Terceira questão orientadora da SDA

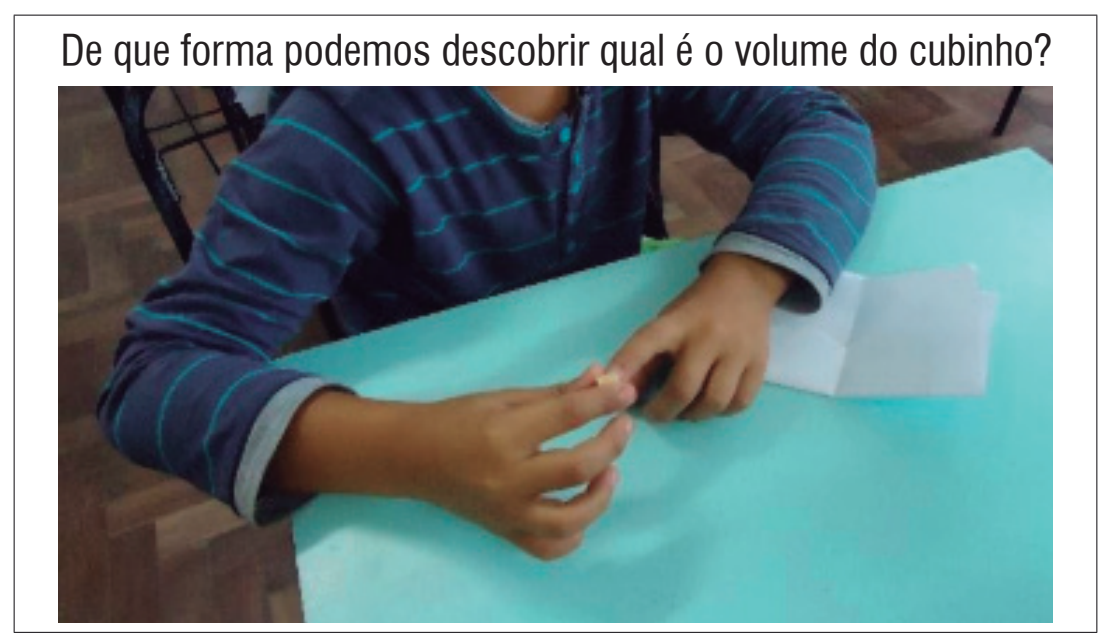

Fonte: Acervo do CluMat

Os alunos ficaram manuseando um cubinho, todavia, mesmo com a discussão anterior relativa à possibilidade de chegar ao volume por meio da medida de comprimento das arestas, associando, inclusive à utilização da régua, eles não conseguiram, de imediato, nos dar uma resposta. Eles não estavam estabelecendo relações entre a unidade discreta e a contínua e as generalizações realizadas. Estavam presos ao campo empírico, associado aos aspectos sensoriais.

Isso nos leva a reconhecer que nem sempre apenas o uso do material sensorial basta para se chegar à essência do conceito, isso nem sempre ocorre de forma imediata e direta. Cumpre, então, superar diversos níveis para chegar ao que Vigotski denomina de conhecimento científico.

el desarrollo de los conceptos científicos habrá de apoyarse de modo indispensable en um determinado nivel de maduración de los conceptos espontáneos, que no pueden ser indiferentes a la formación de los conceptos cinetíficos debido a lo que la experiencia directa nos enseña: el desarrollo de los conceptos científicos resulta posible tan sólo cuando los conceptos espontáneos del niño han alcanzado um nivel determinado, proprio del comiienzo de la edad escolar (VIGOSTKI, 1982, p. 194).

Da mesma maneira as reações dos alunos nos levam a compreender que, muito embora eles cheguem mais facilmente às generalizações empíricas, importantes neste nível de escolarização, faz-se relevante superar 0 empírico para alcançar o pensamento teórico.

Assim, apesar de esperarmos que eles sozinhos chegassem ao $\mathrm{cm}^{3}$ como uma subunidade que poderia ser utilizada para a medida de volume, e percebendo que não tinham familiaridade com as unidades de comprimento, como o centímetro e pouco manuseavam instrumentos de medida, organizamos um momento específico com situações de comparações do material discreto com a régua. A ideia era perceber que 0 auxílio de um instrumento permite chegar à determinação do valor numérico da grandeza de um objeto, sem a comparação direta entre os objetos, e esse valor é expresso em uma determinada unidade padrão. Ou seja, para determinar o volume ocupado por uma certa quantidade de cubinhos, eles não precisariam, necessariamente, contá-los, mas sim, utilizar a 
régua, medir suas arestas e realizar o produto destes três valores, sabendo que a unidade da medida de comprimento era $0 \mathrm{~cm}$.

Após a retomada e a exploração de instrumentos de medida de comprimento, foi organizada uma roda de conversas para que todos pudessem visualizar as caixinhas, os cubinhos e a régua, e voltamos à mesma situação apresentada. Depois de algumas discussões, um estudante, Rafael, fez a seguinte pergunta: "Se quisermos saber quanto espaço essa caixinha cheia ocupa, temos que descobrir o seu volume?", como resposta, Manuela afirmou que "Sim, e temos que medir os lados [apontando para as faces] para achar o volume da caixinha".

As falas de Rafael e Manuela suscitaram uma interessante discussão em que a própria Manuela mostrou aos colegas como fazer para medir as caixas e calcular o volume delas. Aproveitamos a ocasião para introduzir denominações corretas em relação à figuras espaciais, mais especificamente o paralelepípedo, representado nas caixinhas, como faces, arestas, vértices e as dimensões largura, comprimento e altura.

Mesmo Manuela tendo explicado aos colegas que isso poderia ser expresso através da fórmula do volume do paralelepípedo $(V=a \times b \times c)$, julgamos não ser ainda o momento de apresentá-la, pois poderíamos levá-los a se apropriar dela apenas como um "macete" a ser decorado e não como uma síntese que materializa um modo mais rápido e fácil de determinar numericamente o valor da grandeza. Isso foi feito em encontros posteriores.

A partir do que foi exposto, no próximo subitem apresentaremos algumas considerações finais acerca das situações discutidas até o momento.

\section{ALGUMAS CONSIDERAÇÕES FINAIS}

Ao longo dos encaminhamentos de nossa situação desencadeadora desenvolvida por meio das três questões orientadoras aqui apresentadas e das ações que os alunos realizaram para chegar à síntese do cálculo do volume, é possível identificar indícios de aprendizagem sobre volume e capacidade. Percebemos estes indicativos em ações que acompanham o movimento humano de produção de conhecimentos, quando vão das experiências sensoriais de comparação entre os objetos à comparação dos objetos com uma determinada unidade discreta, como modo de atribuir valor às qualidades (grandezas) desse objeto, até a utilização de uma unidade padrão e a aproximação à síntese materializada em uma fórmula.

Com o desenvolvimento da situação desencadeadora de aprendizagem, observamos nas falas dos alunos que várias de suas respostas se assemelham com aspectos relacionados ao movimento lógico-histórico dos conceitos de volume e capacidade. Nesse contexto, entendemos que nosso primeiro encaminhamento, estudo do movimento lógico-histórico destes conceitos através da síntese histórica do conceito, permitiu organizar uma proposta carregada de conceito.

Reconhecendo a importância do movimento lógico-histórico do conceito na organização do ensino, esclarecemos que não se trata aqui de defender a reprodução da história na perspectiva de reinventar a roda, tampouco concebemos que os alunos têm que seguir os mesmos passos que os antigos matemáticos. "Em vez disso, é uma questão de compreender melhor a natureza do conhecimento matemático e de encontrar, dentro de sua estrutura histórica, novas possibilidades de ensino". (RADFORD, 2011, p. 44). Trata-se, assim, de contrapor-se a uma "formulação matemática contemporânea do conteúdo" (RADFORD, 2011, p. 16) centrada no treinamento e na memorização das sínteses cristalizadas pautadas unicamente no rigor matemático. 
Elaborada a partir do processo de estudo da síntese histórica do conceito, entendemos que a nossa SDA, caracterizada enquanto um momento da proposta teórico-metodológica que nos orienta, apresentou possibilidades para os estudantes compreenderem aspectos relacionados à origem do conceito estudado como decorrente de necessidades particularmente humanas através de uma situação intencionalmente planejada.

0 terceiro elemento de organização da nossa proposta consiste na síntese da solução coletiva. Esse momento de síntese nos viabilizou identificar o entendimento dos alunos no que se refere a situação encaminhada, nas formas como solucionaram o problema e nos modos de pensar sobre esse problema. Neste trabalho, especificamente, identificamos que mesmo não chegando à fórmula de cálculo do volume, os alunos aproximaram-se dos conceitos científicos de volume e capacidade a partir de conceitos espontâneos, ou seja, buscaram formas de solução baseadas em suas experiências anteriores.

Os indicativos apresentados nos remetem a pensar no processo de ensinar sobre volume e capacidade nos anos iniciais, ancorado em três considerações. A primeira delas diz respeito ao uso dos materiais sensoriais, no nosso caso, as caixinhas de papel-cartão e os cubinhos do material dourado. Nesse processo de analisar o material que estavam manipulando e ao buscarem formas de possíveis soluções para as questões problemas, aproximavam-se de características comuns que se remetem aos conceitos abordados. Muito embora o objeto da educação escolar seja o pensamento teórico (e este exige ir para além das aparências externas), cumpre ter em mente que, nesta etapa de escolarização, 0 apelo aos materiais é importante para os alunos e pode conduzir a generalizações, a despeito de empíricas. Todavia, cabe ao professor estar ciente que o conhecimento matemático não está nestes materiais e que a sua simples manipulação não permitirá ao aluno apropriar-se do conceito. Nenhum recurso pedagógico carrega em sua aparência o conhecimento, é responsabilidade do professor planejar intervenções intencionais na utilização desses materiais.

A segunda consideração nos conduz à tênue relação entre capacidade e volume. Podemos considerar ambas como qualidades de um objeto e atribuir-Ihes certa quantidade, portanto são mensuráveis com unidades padronizadas ou não. Mas, em se tratando de padronização, as unidades são diferentes. Faz-se necessário, então, que os alunos distingam que: enquanto para 0 volume a unidade-padrão é $0 \mathrm{~m}^{3}$ (metro cúbico), para a capacidade a unidade fundamental é o I (litro). Embora tenhamos percebido indicativos da compreensão dessa relação posteriormente ao que está apresentado neste artigo, foram desenvolvidas na escola outras, ações referentes, especialmente, à unidade de capacidade, utilizando água e instrumentos de medida formais e não formais.

Por fim, entendemos que é possível trabalhar com volume e capacidade nos anos iniciais, chegando à sínteses como fórmulas, embora isto não precise, necessariamente, acontecer. Contudo, há de se tomar cuidado para essas fórmulas não representarem uma inserção ou substituição sem sentido de letras por números, conduzindo os alunos a memorização de regras sem a significação necessária. 0 intuito é de que a utilização de sínteses matemáticas através de fórmulas, quando acontecer, esteja vinculada a materialização de uma síntese derivada do longo movimento humano para encontrar modos de chegar, mais rapidamente e de forma mais eficiente, a resultados numéricos.

\section{REFERÊNCIAS}

ARAUJO, E. S.; MORAES, S. P. G. Dos princípios da pesquisa em educação como atividade. In: MOURA, M. O. de. (org). Educação escolar e pesquisa na teoria histórico-cultural. São Paulo: Layola, 2017. p. 47-70. 
BENDICK, J. Pesos e Medidas. São Paulo: Fundo de Cultura, 1995.

BOYER, C. B. História da matemática. Tradução de Elza F. Gomide. São Paulo:Edgard Blucher, 1974.

BRASIL. Ministério da Educação. Secretaria da Educação Básica. Conselho Nacional de Educação. Base Nacional Comum Curricular: educação é a base. Brasília: MEC, 2017.

CEDRO, W. L. 0 espaço de aprendizagem e a atividade de ensino: 0 clube de matemática, 2004. Dissertação (Mestrado) - Universidade de São Paulo, São Paulo, 2004.

CEDRO, W.L; NASCIMENTO, C.P. Dos métodos e das metodologias em pesquisas educacionais na teoria-histórico cultural. In: MOURA, M.O.(org.). Educação escolar e pesquisa na teoria histórico-cultural. São Paulo: Loyola, 2017.

CREASE, R. P. A medida do mundo: a busca por um sistema universal de pesos e medidas. Tradução de George Schlesinger. Rio de Janeiro: Zahar, 2013.

DAVYDOV, V. V. Tipos de generalización en la enseñanza. Ciudad de La Habana: Editorial Pueblo y Educación, 1982.

DAVYDOV, V. V. La enseñanza escolar y el desarrollo psiquico. Ciudad de Moscu: Editorial Progresso, 1988.

EVES, H. Introdução à história da matemática. Tradução de Hygino. Domingues. Campinas, São Paulo: UNICAMP, 2004.

KOPNIN, P. A dialética como lógica e teoria do conhecimento. Rio de janeiro: Civilização Brasileira, 1978.

LEONTIEV, A. N. 0 desenvolvimento do psiquismo. Lisboa: Horizonte Universitário, 1978.

LIMA, E. L. Medida e forma em geometria: comprimento, área, volume e semelhança. Rio de Janeiro: GRAFTEX, 1991.

LOPES, A. R. L. V.; VAZ, H. G. B. 0 movimento de formação docente no ensino de geometria nos anos iniciais. Educação \& Realidade, Porto Alegre, v. 39, n. 4, p. 1003-1025, out./dez. 2014. Disponível em: http://www.ufrgs.br/edu_realidade. Acesso em: 01 jun. 2020.

MORETTI, V. D., ASBAHR, F. S. F.; RIGON, A. J. 0 humano no homem: os pressupostos teórico-metodológicos da teoria histórico-cultural. Psicologia \& Sociedade, v. 23, n.3, p. 477-485, 2011. Disponível em: https://bit.ly/31rZdP5. Acesso em: 01 jun. 2020.

MOURA, M. 0. de. A atividade de ensino como unidade formadora. Bolema, Rio Claro, v. 12, p. 29-43, 1996.

MOURA, M. O. de. A atividade de ensino como ação formadora. In: CASTRO, A.; CARVALHO, A. (org.). Ensinar a ensinar: didática para a escola. São Paulo: Pioneira, 2001.

MOURA, M. 0. de. Educar con las matemáticas: saber específico y saber pedagógico. Revista Educación y Pedagogía, v. 23, n.59, p. 48- 57, enero/abril, 2011.

MOURA, M. 0. de. et al. Atividade orientadora de ensino: unidade entre ensino e aprendizagem. Revista Diálogo Educacional, Curitiba, v.10, n. 29, p. 205-229, jan./abr., 2010. 
MOURA, M. O. de; LANNER de MOURA, A. R. Escola: um espaço cultural. Matemática na Educação Infantil: conhecer, re(criar) - um modo de lidar com as dimensões do mundo. São Paulo: Diadema/ Secel, 1998.

MOURA, M. 0. de; SFORNI, M. S. de F.; LOPES, A. R. L. V. A objetivação do ensino e o desenvolvimento do modo geral da aprendizagem da atividade pedagógica. In: MOURA, M. 0. de. (Org). Educação escolar e pesquisa na teoria histórico-cultural. São Paulo: edições Layola, 2017.

MOURA, M.O.; LOPES, A.R.L.V.; ARAUJO, E.S.; CEDRO, W. L. (org.). Atividades para 0 ensino de matemática nos anos inicias da educação básica: Volume II-Medidas. São Paulo, LABEDUC: USP. 2018.

NÚÑEZ, I. B. Vygotsky, Leontiev e Galperin: formação de conceitos e princípios didáticos. Brasília: Líber Livro, 2009.

PASQUALINI, J. C. 0 desenvolvimento do psiquismo e o ensino escolar. In: PASQUALINI, J. C.; TSUHAKO, Y. N. (org.). Proposta pedagógica para a Educação Infantil do Sistema Municipal de Ensino de Bauru/ SP. (Recurso Eletrônico). Bauru: Secretaria Municipal de Educação, 2016.

PINO, A. As marcas do humano: às origens da constituição cultural da criança na perspectiva de Lev S. Vigotski. São Paulo, SP: Cortez, 2005.

RADFORD, L. Cognição matemática: História, Antropologia e Epistemologia. Sociedade Brasileira de História da Matemática. São Paulo. Editora Livraria da Física, 2011.

RUBTSOV, V. A atividade de aprendizado e os problemas referentes à formação do pensamento teórico dos escolares. In: GARNIER, C. et al. (org.). Após Vygotsky e Piaget: perspectivas social e construtivista escolas russa e ocidental. Porto Alegre: Artes Médicas, 1996.

SILVA, I. História dos pesos e medidas. São Carlos: EdUFSCAr, 2010.

VIGOTSKI, L. S. Obras escogidas. Tradução de José Maria Bravo. Moscou: Editorial Pedagógica, 1982. Tomo II.

VIGOTSKI, L. S. A formação social da mente: o desenvolvimento dos processos psicológicos superiores. 5. ed. São Paulo: Martins Fontes, 1994.

VIGOTSKI, L. S. A construção do pensamento e da linguagem. Tradução de Paulo Bezerra. São Paulo: Martins Fontes, 2000.

VIGOTSKI, L. S. A formação social da mente. 6. ed. São Paulo: Martins Fontes, 2002. 1999.

VIGOTSKI, L. S. Imaginação e criatividade na infância. Tradução de João Pedro Fróis. São Paulo: WMF Martins Fontes, 2014.

RECEBIDO EM: 29 jun. 2020

CONCLUÍDO EM: 20 set. 2020 
